\title{
Modeling of a Cubic Antiferromagnetic Cuprate Super-Cage
}

\author{
Hans Hermann Otto \\ Materialwissenschaftliche Kristallographie, TU Clausthal, Clausthal-Zellerfeld, Germany \\ Email: hhermann.otto@web.de
}

Received 18 May 2015; accepted 2 August 2015; published 5 August 2015

Copyright (C) 2015 by author and Scientific Research Publishing Inc. This work is licensed under the Creative Commons Attribution International License (CC BY). http://creativecommons.org/licenses/by/4.0/

(c) (i) Open Access

\section{Abstract}

Convex polyhedral cuprate clusters are being formed through lateral frustration when the $a$ and $c$ lattice parameters of the tetragonal $\mathrm{ACuO}_{2}$ infinite layer structure will become identical by substitution of a large cation $\left(\mathrm{A}=\mathrm{Ba}^{2+}\right)$. However, the corner-shared $\mathrm{CuO}_{2}$ plaquettes of the infinite network suffer a topotactic rearrangement forming edge-connected units, for instance $\mathrm{Cu}_{18} \mathrm{O}_{24}$ cages (polyhedron notation $\left[4^{6} 4^{12} 3^{8}\right]$ ) with $<90^{\circ}$ ferromagnetic super-exchange interaction as found in cubic $\mathrm{BaCuO}_{2}$. Cage formation via a hypothetical tetragonal $\mathrm{BaCuO}_{2}$ compound (space group $\mathrm{P4} /$ $\mathrm{nmm}$ ) will be discussed. The possibility to construct a cuprate super-cage with $\mathrm{m} 3 \mathrm{~m}$ symmetry (polyhedron notation $\left[4^{6} 4^{12} 4^{24} 3^{8}\right]$ ) is being reported. This super-cage still consists of edge-connected $\mathrm{CuO}_{2}$ plaquettes when fully decorated with copper ions, but with different curvatures, arranged in circles of 9.39 Å of diameter with $139.2^{\circ} \mathrm{Cu}-\mathrm{O}$ - $\mathrm{Cu}$ antiferromagnetic super-exchange interaction. On the one hand, the realization of such a quite stable cuprate super-cage as a candidate for high- $\mathrm{T}_{\mathrm{c}}$ superconductivity depends on whether a template of suitable size such as the $\mathrm{N}\left(\mathrm{CH}_{3}\right)_{4}^{+}$ cation or $\mathrm{C}\left(\mathrm{CH}_{3}\right)_{4}$ enables its formation, and on the other hand the cage can further be stabilized by highly charged cations located along the [111] direction. Synthesis options will be proposed based on suggested cage formation pathways. An X-ray powder pattern was calculated for a less dense cluster structure of $\operatorname{Im} 3 \mathrm{~m}$ space group with a lattice parameter of $a=14.938 \AA$ and two formula units of $\mathrm{Cu}_{46} \mathrm{O}_{51}$ to facilitate future identification. Characteristic X-ray scattering features as identification tool were obtained when the electron distribution of the hollow polyhedron was approximated with electron density in a spherical shell.

\section{Keywords}

Super-Cage, Convex Polyhedra, Cuprate, $\mathrm{BaCuO}_{2}, \mathrm{~T}-\mathrm{CuO}$, Superconductivity, Bond Strength, Frustration, X-Ray Pattern 


\section{Introduction}

Almost thirty years of intense research on high- $T_{c}$ superconductors have elapsed this year. Since the discovery of high- $T_{c}$ superconductivity by Bednorz and Müller in 1986 [1], rich results have been obtained in distinct fields of science and technology, physics, solid state chemistry, material science and crystallography. Many comprehensive papers [2]-[4] report on the great variety of new crystal structures of superconducting compounds, often showing an optimum hole doping as intrinsic quality. Owing to the ability of the $\mathrm{d}^{9}$ transition metal ion to form, apart from 3D networks, chains, ladders, and small and medium clusters, copper compounds are among the most interesting phases. Low-dimensional quantum spin systems are of considerable theoretical and experimental interest together with new applications to which they may lead. $\mathrm{The}^{\mathrm{Cu}^{2+}}$ ion owes its network forming property to a high electronegativity, similar to $\mathrm{Si}^{4+}$, but in contrast to the tetrahedral networks of $\mathrm{Si}^{4+}$, $\mathrm{Cu}^{2+}$ mainly forms oxo-compounds with chains and networks of connected "octahedra". In the crystal structure of $\mathrm{CuSiO}_{3}$ [5] [6], isostructural to $\mathrm{CuGeO}_{3}$, such "octahedral" edge-connected chains are combined with ideally stretched corner-connected silicate tetrahedral ones.

Cupric oxide cages of both corner-connected and edge-shared $\mathrm{CuO}$ octahedra, formed around 6-membered silicate rings and $\mathrm{H}_{2} \mathrm{O}$, are found in the crystal structure of the gemstone dioptase, $\mathrm{Cu}_{6} \mathrm{Si}_{6} \mathrm{O}_{18} \cdot 6 \mathrm{H}_{2} \mathrm{O}$. Crystal water can escape on heating trough openings in the cages. Whereas magnetic properties have been extensively investigated, the synthesis of pure dioptase is not successful yet but may benefit from ideas of cluster formation expressed in this work.

It came as a great surprise when Sigrist et al. [7] succeeded in synthesizing $\mathrm{Ca}_{0.86} \mathrm{Sr}_{0.14} \mathrm{CuO}_{2}$, a very simple compound of tetragonal symmetry (space group P4/mmm) with lattice parameters of $a=3.8611$ (2) $\AA$ and $c=$ 3.1995(2) $\AA$ and $Z=1$, which they named parent structure of the layered high-temperature superconductors. Other authors call it infinite-layer or all-layer compound owing to the feature that the structure may be described as oxygen-deficient perovskite that has lost a complete oxygen layer thus making the large $\mathrm{Ca}^{2+}$ or $\mathrm{Sr}^{3+}$ cations [8]-coordinated instead of [12]-coordinated and leaving infinite $\mathrm{CuO}_{2}$ layers with square-coordinated $\mathrm{Cu}^{2+}$ instead of octahedral layers. Figure 1 depicts the $\mathrm{CuO}_{2}$ net of the parent structure, one of the building blocks of most high- $\mathrm{T}_{\mathrm{c}}$ superconducting compounds. It should be noted that the $\mathrm{CuO}_{4}$ squares in the infinite $\mathrm{CuO}_{2}$ layers are corner-connected.

Recently, Siemons [8] discovered that cupric oxide could be epitaxially grown as thin film on a (100) $\mathrm{SrTiO}_{3}$ substrate in a tetragonally elongated rocksalt structure with lattice parameters of $a=3.905 \AA$ and $c=5.32 \AA$, as a result of the Jahn-Teller effect [9]. The existence of such an edge-connected T-CuO net is exciting as it will serve to support my ideas of cagey cluster formation and synthesis routes. Without substrate support, the planar $\mathrm{CuO}$ net suffers folding in two directions resulting in the monoclinic tenorite structure. The folding of the $\mathrm{T}-\mathrm{CuO}$ net may be accompanied by a latent $\mathrm{Cu}^{1+}-\mathrm{Cu}^{3+}$ disproportionation, which can help to better understand

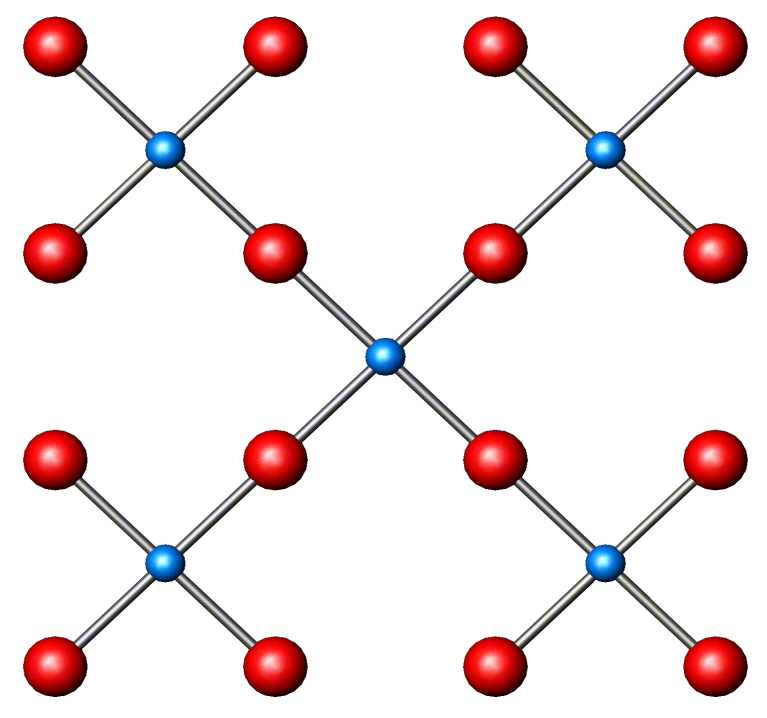

Figure 1. Corner-connected cuprate plaquettes, representing the building units of high- $\mathrm{T}_{\mathrm{c}}$ superconductors. 
the high- $\mathrm{T}_{\mathrm{c}}$ multiferroic properties and frustration induced spiral spin-ordering of this compound.

Turning back to the parent structure, the already known crystal structures of similar compounds of the larger group II elements $\mathrm{Sr}$ and $\mathrm{Ba}$ are very complex and less dense compared to the parent structure. The cubic compound $\mathrm{BaCuO}_{2}$ showing distinct copper-oxygen clusters has really a large lattice parameter of $a=18.2855(3) \AA$ and contains $Z=90$ formula units in its unit cell. In contrast to the infinite layer structure, the $\mathrm{CuO}_{4}$ quadrilaterals of the clusters are edge-connected. The $\mathrm{Cu}_{18} \mathrm{O}_{24}^{12-}$ polyhedral cluster is depicted in Figure 2.

The question arises, why $\mathrm{BaCuO}_{2}$ does not exist in the simple prototypic structure of the parent compound, explicitly disregarding air-sensitive and highly strained $\mathrm{BaCuO}_{2}$ epitaxial layers. Since the $<90^{\circ}$ super-exchange interaction of edge-connected clusters is unfavourable for the development of superconducting properties, the idea emerges to construct a super-cage cluster of cuprate units with larger radius of curvature and then $>90^{\circ}$ $\mathrm{Cu}-\mathrm{O}-\mathrm{Cu}$ antiferromagnetic super-exchange interaction favouring high- $\mathrm{T}_{\mathrm{c}}$ superconductivity.

Promising new opportunities such as crystal structure prediction from first principles (Woodley and Catlow [10]) or application of advanced tiling theory for the systematic generation of 4-connected crystalline networks (Forster et al. [11]) have stimulated condensed matter sciences. In addition, the recent discovery of a new class of convex Goldberg polyhedra (Schein and Gayed [12]) should encourage scientists to synthesize such cages. For example, the successful synthesis of earlier predicted, yet not perfectly smooth $\mathrm{B}_{40}$ boronspherene shows what possible is [13]. The cuprate super-cage may as well a worthwhile object of synthesis effort in the near future.

A summary assessment of synthesis routes and crystal chemistry of infinite-layer compounds in contrast to the cubic cluster compound $\mathrm{BaCuO}_{2}$ suggests an explanation of cluster formation, finally leading to the proposal of a cuprate super-cage structure.

\section{Planar Cuprate Networks versus Polyhedral Clusters}

The formation and crystal chemistry of two $\mathrm{ACuO}_{2}$ structure types are summarized in the appendix: the simple "infinite-layer" $\mathrm{Ca}_{0.86} \mathrm{Sr}_{0.14} \mathrm{CuO}_{2}$ structure type and the very complex $\mathrm{BaCuO}_{2}$ type. $\mathrm{Ca}_{0.86} \mathrm{Sr}_{0.14} \mathrm{CuO}_{2}$ is tetragonal, space group P4/mmm, with lattice parameters of $a=3.8611(2) \AA, c=3.1995(2) \AA$. In contrast, the $\mathrm{BaCuO}_{2}$ structure is cubic, space group $\operatorname{Im} 3 \mathrm{~m}$, but shows a very large lattice parameter of $a=18.2855$ (3) $\AA$, obviously indicative of a conflicting formation scenario. A series of compounds are known with infinite-layer structure type with steadily increasing $c$ lattice parameters, obtained by the substitution of $\mathrm{Ca}^{2+}$ by the larger $\mathrm{Sr}^{2+}$ and $\mathrm{Ba}^{2+}$ ions (see Table 1).

For the case of an unstrained fictive infinite-layer $\mathrm{BaCuO}_{2}$ end member the $c$ lattice parameter would reach or exceed the separation of the initially larger $a$ parameter. At that point the two-dimensional $\mathrm{CuO}_{2}$ nets of the
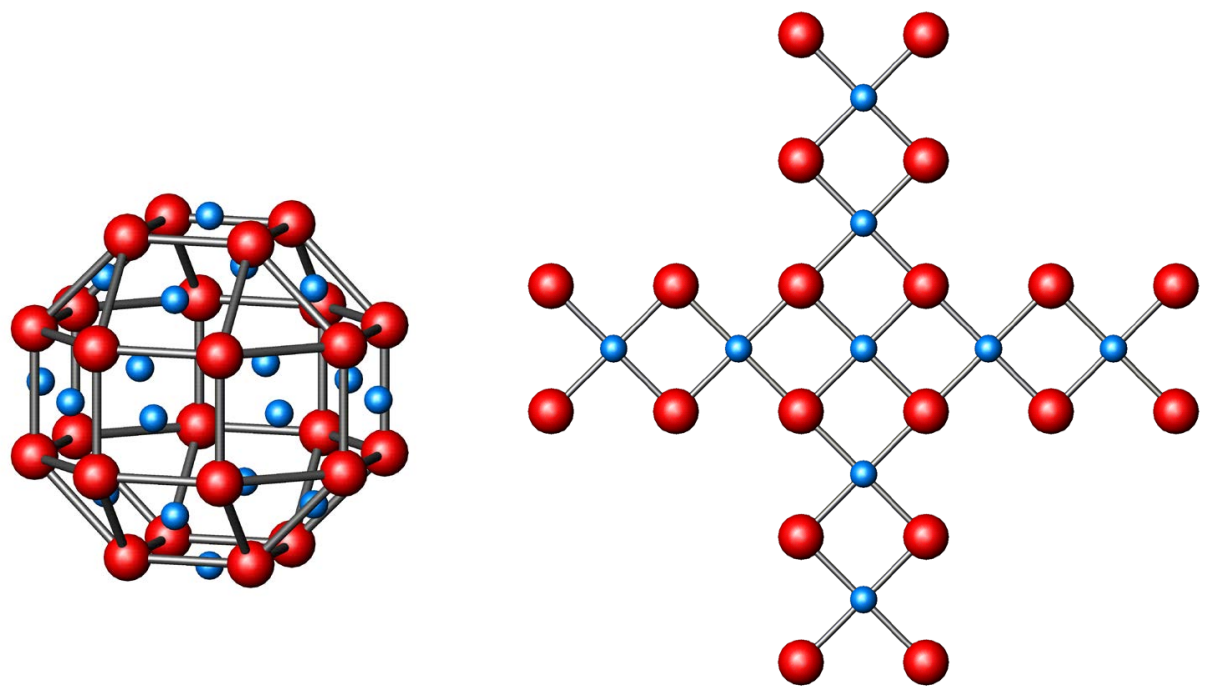

Figure 2. (a) $\mathrm{Cu}_{18} \mathrm{O}_{24}^{12-}$ cluster of the cubic $\mathrm{BaCuO}_{2}$ structure consisting of closed strips of edgesharing $\mathrm{CuO}_{4}$ squares. (b) Unfolded hemi-polyhedron of that cluster showing edge-connected $\mathrm{CuO}$ units. 
Table 1. Infinite-layer compounds of $\mathrm{ACuO}_{2}$ composition, $\mathrm{A}=\mathrm{Ca}, \mathrm{Sr}, \mathrm{Ba} .<\mathrm{r}_{\text {a.e. }}>$ represents the mean radius in $\AA$ of the alkaline earth ions according to the formula in the surrounding of 8 oxygen atoms.

\begin{tabular}{|c|c|c|c|c|}
\hline \multirow[t]{2}{*}{ Formula } & \multicolumn{2}{|c|}{ Lattice parameters } & \multirow[t]{2}{*}{$<\mathrm{r}_{\mathrm{a} . \mathrm{e} .}>$} & \multirow[t]{2}{*}{ Remark } \\
\hline & $\mathrm{a}(\AA)$ & $c(\AA)$ & & \\
\hline $\mathrm{BaCuO}_{2}$ & $3.90 ?$ & 4.08 & 1.42 & highly strained \\
\hline $\mathrm{BaCuO}_{2}$ & 3.96 & $3.96^{*}$ & 1.42 & fictive values \\
\hline $\mathrm{Ba}_{0.5} \mathrm{Sr}_{0.5} \mathrm{CuO}_{2}$ & $3.92(3.94)$ & $2 \cdot 3.965$ & 1.34 & orthorhombic \\
\hline $\mathrm{Ba}_{0.33} \mathrm{Sr}_{0.67} \mathrm{CuO}_{2}$ & 3.93 & 3.477 & 1.3133 & \\
\hline $\mathrm{SrCuO}_{2}$ & 3.926 & 3.432 & 1.26 & \\
\hline$\left(\mathrm{Sr}_{0.7} \mathrm{Ca}_{0.3}\right)_{0.9} \mathrm{CuO}_{2}$ & 3.902 & 3.350 & 1.218 & $T_{c}=110 \mathrm{~K}(p$-type $)$ \\
\hline $\mathrm{Sr}_{0.33} \mathrm{Ca}_{0.67} \mathrm{CuO}_{2}$ & 3.878 & 3.259 & 1.167 & \\
\hline $\mathrm{Sr}_{0.14} \mathrm{Ca}_{0.86} \mathrm{CuO}_{2}$ & 3.861 & 3.200 & 1.1396 & prototypic compound \\
\hline $\mathrm{Sr}_{0.09} \mathrm{Ca}_{0.91} \mathrm{CuO}_{2}$ & 3.858 & 3.20 & 1.1326 & \\
\hline $\mathrm{CaCuO}_{2}$ & 3.85 & 3.17 & 1.12 & extrapolated parameters \\
\hline $\mathrm{Ca}_{0.98} \mathrm{CuO}_{2}$ & 3.856 & 3.181 & 1.12 & high gas-pressure synthesis \\
\hline $\mathrm{S}_{0.84} \mathrm{Nd}_{0.16} \mathrm{CuO}_{2}$ & 3.942 & 3.38 & & $T_{c}=43 \mathrm{~K}(n$-type $)$ \\
\hline
\end{tabular}

${ }^{*)}$ lattice parameters obtained by bond strength—-bond length calculations.

infinite-layer structure turn into different sorts of cuprate clusters, characteristic for the actual $\mathrm{BaCuO}_{2}$ structure. This rolling-up of the $\mathrm{CuO}_{2}$ nets forming clusters is explained by lattice spacing frustration. This occurs when the separation between the $\mathrm{CuO}_{2}$ layers of the infinite-layer structure exceeds the translation period $a$ within the layer. In this case infinite $\mathrm{CuO}_{2}$ nets have the chance to be formed in all three directions but are not allowed to exist in all.

The end member $\mathrm{BaCuO}_{2}$, as already mentioned, hardly exists in the parent structure as less strained compound. Its fictive lattice parameters shown in Table 1 were obtained by bond strength - bond length calculation. For $\mathrm{Ba}^{2+}$ surrounded by 8 oxygen atoms in a regular fashion, one obtains the $\mathrm{Ba}-\mathrm{O}$ distance of $d=2.800 \AA$, using the empirical formula of Brown and Shannon [14] that was rewritten into the specialized equation $d=d_{0} / \mathrm{s}^{1 / N}$, where $\mathrm{s}$ represents the bond valence (valence divided by the coordination number). The parameters used are $d_{0}=$ $2.297 \AA$ and $N=7$ [15]. The length of the $c$ axis is then $\sqrt{2} \cdot d=3.96 \AA$, equal to the $a$ parameter. It would be also possible to obtain an extrapolation of the $a$ and $c$ lattice parameters, respectively when these parameters of the compound series are plotted against the mean ionic radii of the group II elements (see Figure 3). The lattice parameters $a$ increase only slightly from about $3.85 \AA$ to $3.96 \AA$ owing to the strength of the covalent bonds of the planar $\mathrm{CuO}_{2}$ nets thus obviating much strain. More crystal-chemical details are summarized below as supplementary information.

The results provide a possible explanation of the astonishing structural differences between the infinite-layer and the cubic $\mathrm{BaCuO}_{2}$ structures. The degeneracy of the lattice parameters is all equal for of $\mathrm{BaCuO}_{2}$ in the fictive all-layer structure, or at least the $c$ lattice parameter exceeding the $a$ lattice parameter. This has the consequence that this structure is non-existent, because it is impossible that $\mathrm{CuO}_{2}$ layers can be formed in all three dimensions, only fragments of such layers could grow. However, potential layer fragments will be unstable against folding and will close into clusters, a mechanism well consistent with cubic symmetry. The formation of different clusters can reduce the strain in the structure and finally leads to the observed large unit cell of the actual structure. The degeneracy of lattice spacing is evidently the reason for the formation of the complex $\mathrm{BaCuO}_{2}$ structure required to overcome the lateral frustration.

Let us draw attention again to the very simple $\mathrm{BaCuO}_{2}$ stoichiometry. Does the structure retain some memory of its formation history? Could it be that the first small nuclei formed, occur as infinite-layer blocks with simple 


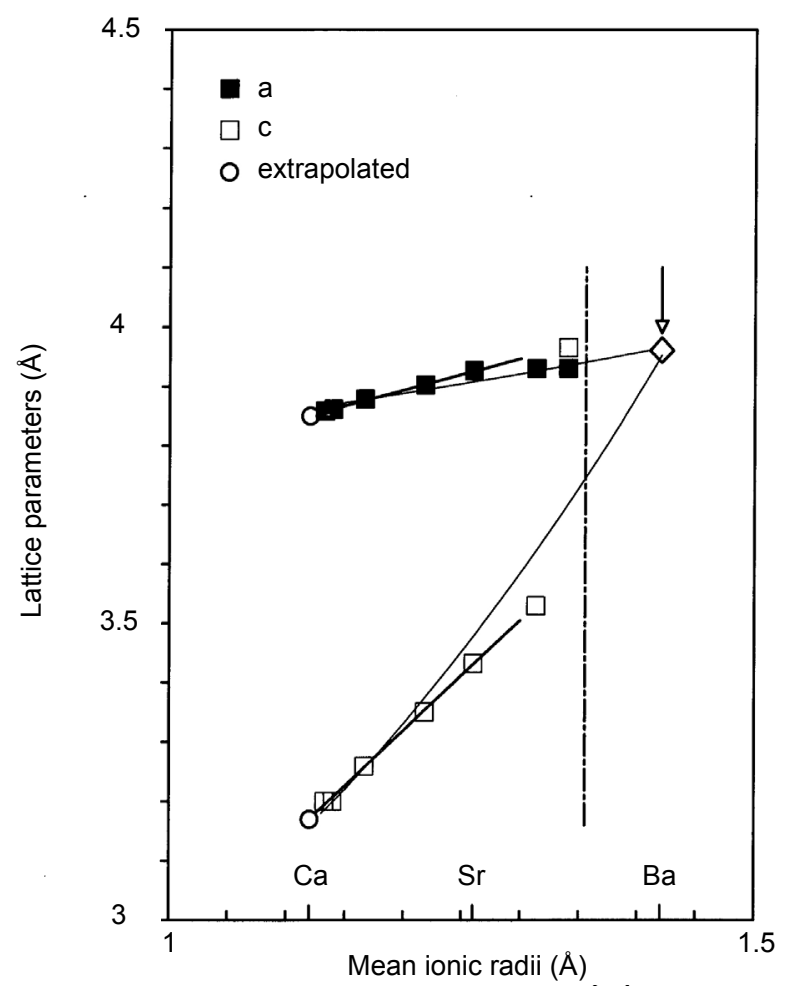

\begin{abstract}
Figure 3. Plot of lattice parameters versus mean ionic radii for infinite layer compounds (square symbols) as listed in Table 1 . The circles indicate extrapolated values for pure, non-existent $\mathrm{CaCuO}_{2}$ according to a linear regression. The arrow-marked diamond symbol depicts the fictive parameter ( $a$ and $c$ equal) for $\mathrm{BaCuO}_{2}$ in the infinite layer structure, which is non-existent in this structure type under ambient conditions. The vertical dashed line indicates the assumed phase borderline between the infinite-layer and the cubic $\mathrm{BaCuO}_{2}$ prototypes.
\end{abstract}

stoichiometry, maybe as three-dimensional chessboard-like ordered assemblies, and then pass on this simple stoichiometry before the structural transformation to cubic $\mathrm{BaCuO}_{2}$ happens? If so, we have to explain the origin of different connections of the $\mathrm{CuO}_{2}$ squares, first being corner-connected and then edge-connected.

Fluctuations in the concentration or growth conditions (thermodynamic variables) are responsible for structural distortions, which have been observed by electron-microscopy in the parent structure. For instance, occasionally small clusters in the form of $\mathrm{CuO}_{5}$ pyramids exist in compounds of high $\mathrm{Ba}$ content near the end member composition, but the general layer structure still persists [16]. Thus the members with high Ba content already indicate a certain readiness for structural phase transition.

If the $c$ lattice parameter approaches the $a$-axis length, oxygen can penetrate into the otherwise oxygen-free $\mathrm{Ba}$ layer with simultaneous oxygen depletion of the $\mathrm{CuO}_{2}$ layer. The stoichiometry tells us that in the limiting case one $\mathrm{T}-\mathrm{CuO}$ layer with twice as many $\mathrm{Cu}$ could sandwich two $\mathrm{BaO}$ layers. Locally, nano-scaled phase separation may occur into rocksalt-type $\mathrm{BaO}$ and $\mathrm{T}-\mathrm{CuO}$, but a complete separation is excluded because of the high reactivity of $\mathrm{BaO}$. The lattice parameter of $\mathrm{BaO}$ of $a=5.534 \AA$ matches almost perfectly that of T-CuO with $a \cdot \sqrt{2}=3.905 \cdot \sqrt{2} \AA=5.523 \AA$, strongly suggesting the possibility for a topotactic intergrowth at nano-scale dimension. Then we are faced with edge-connected $\mathrm{T}-\mathrm{CuO}$ fragments containing peripherally edge-dangling bonds, which may easily curl up into polyhedral cages. Another possibility is the existence of a hypothetical $\mathrm{BaCuO}_{2}$ phase with tetragonal symmetry that would show nearly perfect lattice dimensions for a topotactic reaction, too. Figure 4 illustrates this model structure of space group P4/nmm with lattice parameters of $a=3.87 \AA$ and $c=8.20$ $\AA$. A puckered edge-connected $\mathrm{CuO}$ layer of alternatively up and down directed $\mathrm{CuO}$ pyramids is sandwiched between layers of $\mathrm{BaO}$ with 9-fold oxygen environment, representing the average of the rocksalt and the perovskite coordinations $([6]+[12]) / 2=[9])$, similar to the $\mathrm{La}^{3+}$ coordination in $\mathrm{La}_{2} \mathrm{CuO}_{4}$. Table 2 and Table 3 show the atomic coordinates and bond lengths and bond angles, respectively. X-ray powder data are given in Table 4. 
Notably, a long time ago this simulated structure was considered responsible for unstable superconductivity at very high $T_{c}=220 \mathrm{~K}$ [17]. Its formation as ultrathin film, possibly peroxide-expanded because of oxygenation during the experiment, was conjectured as intermediate reaction layer between the chosen (110)- $\mathrm{SrTiO}_{3}$ substrate and the $\mathrm{YBa}_{2} \mathrm{Cu}_{3} \mathrm{O}_{7-\mathrm{X}}$ superconducting film. More recently, it was assumed that filamentory superconductivity at $220 \mathrm{~K}$ is caused by a small content of oxygen depleted cupric oxide $\mathrm{CuO}_{1-\mathrm{x}}$ within the multi-phase sample [18]-[20]. Crystallographic data of the different $\mathrm{BaCuO}_{2}$ phases are compared in Table 5 .

Remarkably, $\mathrm{BaO}$ transforms under a pressure of $18 \mathrm{GPa}$ into the $\mathrm{PbO}$ type sheet structure with a P4/nmm space group identical to that of the $\mathrm{BaCuO}_{2}$ model structure, with lattice parameters of $a=4.397(7) \AA$ and $c=$ 3.196(5) $\AA[21]$. In this structure $\mathrm{Ba}$ is located off-centre between 8-coordinating oxygen atoms.

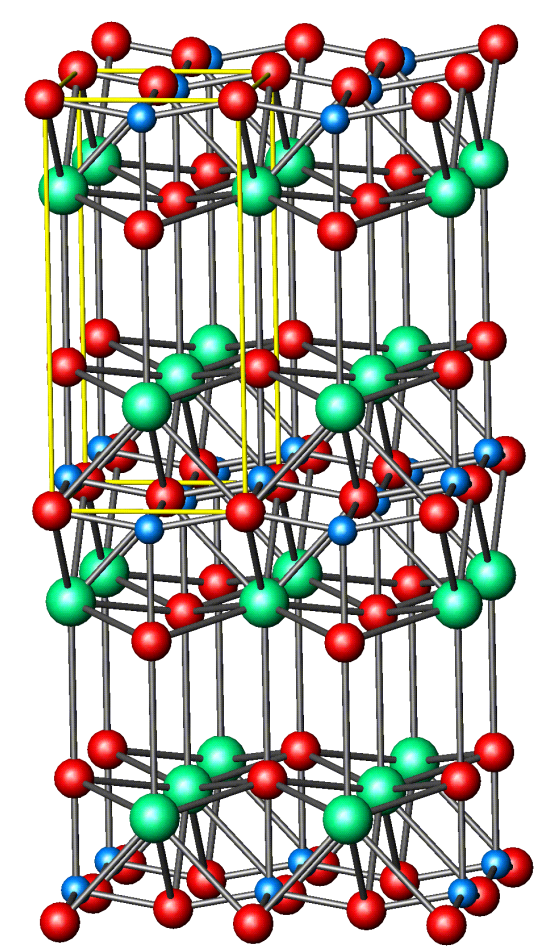

Figure 4. Hypothetical crystal structure of tetragonal $\mathrm{BaCuO}_{2}$ with $a=3.87 \AA, c=8.20 \AA$, space group P4/nmm (No. 129/1). Unit cell yellow outlined, Cu blue, Ba green, O red.

Table 2. Atomic coordinates of hypothetical $\mathrm{BaCuO}_{2}$, tetragonal space group P4/nmm (No. $129 / 1$ ) with lattice parameters of $a=3.87 \AA, c=8.20 \AA, Z=2$.

\begin{tabular}{ccccc}
\hline Atom & Site & $\mathrm{x}$ & $\mathrm{y}$ & $\mathrm{z}$ \\
$\mathrm{Cu}$ & $2 \mathrm{c}$ & 0.5 & 0 & -0.043 \\
$\mathrm{Ba}$ & $2 \mathrm{c}$ & 0.5 & 0 & 0.255 \\
$\mathrm{O}(1)$ & $2 \mathrm{a}$ & 0 & 0 & 0 \\
$\mathrm{O}(2)$ & $2 \mathrm{c}$ & 0 & 0.5 & 0.315 \\
\hline
\end{tabular}

Table 3. Bond lengths $(\AA)$ and bond valence sums, respectively of hypothetical $\mathrm{BaCuO}_{2}$.

\begin{tabular}{ccc}
\hline Atoms & $\mathrm{Cu}$ & $\mathrm{Ba}$ \\
\hline $\mathrm{O}(1)$ & $4 \times 1.9669$ & $4 \times 2.8489$ \\
$\mathrm{O}(2)$ & 2.2304 & $4 \times 2.7804$ \\
& & 3.5260 \\
Bond valence sum & $2.01[5]$ & $1.99[9]$ \\
\hline
\end{tabular}


Table 4. Calculated $\mathrm{X}$-ray powder pattern for hypothetical $\mathrm{BaCuO}_{2}\left(\mathrm{Cu}-\mathrm{K} \alpha_{1}\right.$ radiation, $\lambda=$ $1.5406 \AA)$.

\begin{tabular}{cccc}
\hline$\Theta$ & $\mathrm{d}$ & $\mathrm{I}_{\text {calc }} / \mathrm{I}_{0}$ & $\mathrm{hkl}$ \\
\hline 10.871 & 8.200 & 100 & 001 \\
21.658 & 4.100 & 68 & 002 \\
25.430 & 3.500 & 32 & 101 \\
32.737 & 2.733 & 29 & 003 \\
40.366 & 2.2366 & 9 & 103 \\
44.142 & 2.0500 & 36 & 004 \\
46.917 & 1.9350 & 62 & 200 \\
48.287 & 1.8833 & 7 & 201 \\
52.233 & 1.7499 & 8 & 202 \\
54.115 & 1.6934 & 8 & 211 \\
58.385 & 1.5793 & 13 & 203 \\
61.345 & 1.5100 & 2 & 105 \\
63.578 & 1.4662 & 5 & 213 \\
66.380 & 1.4072 & 20 & 204 \\
68.524 & 1.3683 & 8 & 220 \\
68.615 & 1.3667 & & 006 \\
\hline & & 2 &
\end{tabular}

Table 5. Comparison of crystallographic data for distinct $\mathrm{BaCuO}_{2}$ phases.

\begin{tabular}{ccccccc}
\hline Symmetry & $\mathrm{a}(\AA)$ & $\mathrm{c}(\AA)$ & $\mathrm{V}_{0}\left(\AA^{3}\right)$ & $\mathrm{Z}$ & $\mathrm{D}_{\mathrm{x}}\left(\mathrm{g} / \mathrm{cm}^{3}\right)$ & Comment \\
\hline cubic & 18.25 & - & 6113.93 & 90 & 5.69 & cluster \\
& 3.96 & 3.96 & 62.099 & 1 & 6.23 & frustrated \\
tetragonal & 3.90 & 4.08 & 62.057 & 1 & 6.23 & strained \\
& 3.87 & 8.20 & 122.81 & 2 & 6.30 & hypothetical \\
\hline
\end{tabular}

The investigation of frustration is a current research field of physics and mostly applied to spin systems and magnetism. In geometrically frustrated structures magnets are unable to attain order by virtue of their local geometric arrangement. A prominent example is the frustration-induced spiral ordering of spins of the high- $\mathrm{T}_{\mathrm{c}}$ multiferroic monoclinic $\mathrm{CuO}$ (Kimura et al. [22] [23]). However, pure mechanical systems can also be frustrated. Examples are the multitude of ice structures and the way, in which the hydrogen atoms of the polar $\mathrm{H}_{2} \mathrm{O}$ molecule can order with two hydrogen atoms nearby and two further away from the oxygen atom. A further example of a frustrated system is the isotropic negative thermal expansion (contraction) of $\mathrm{ZrW}_{2} \mathrm{O}_{8}$ over a wide temperature range including room temperature owing to transverse thermal motion of a non-bonded oxygen atom on the apex of the $\mathrm{ZrO}_{8}$ octahedron. Here, the mechanical under-constraint is reminiscent of magnetic spin systems (Ramirez et al. [24]). In our case of the fictive infinite-layer structure of $\mathrm{BaCuO}_{2}$ we are dealing simply with a sort of lateral frustration. This may simply be considered as the inability of structural building units to attain order in the simplest arrangements possible. Any which way nature reacts to this situation, the cubic $\mathrm{BaCuO}_{2}$ structure is unprecedented in its complexity.

Although p-type current carriers are found for the cubic $\mathrm{BaCuO}_{2+\delta}$ prototype with $\delta=0.07$, superconductivity was never observed. This is attributed not so much to a non-optimum hole doping as to the $<90^{\circ} \mathrm{Cu}-\mathrm{O}-\mathrm{Cu}$ super-exchange interaction and the stiffness of the edge-sharing cuprate strips, which form the clusters and show a 
distance of less than $2.7 \AA$ among $\mathrm{Cu}$ atoms, compared with more than $3.8 \AA$ of the corner-sharing cuprate layer of superconducting compounds.

\section{Proposal for a Cuprate Super-Cage}

The topology and stoichiometry of cuprate cages can be described with the symbol $\left[\sum p_{i} f_{i}\right]$ denoting a convex polyhedron with polygon multiplicities $p_{i}$ of faces $f_{i}$. The number of edges e of the polyhedron counts as

$$
\sum e=\frac{1}{2} \sum p_{i} f_{i} .
$$

Applying Euler's topologic invariant for convex polyhedra [25],

$$
\sum c+\sum f-\sum e=2
$$

the number of corner $c$ yields

$$
\sum c=\frac{1}{2} \sum p_{i} f_{i}-\sum f_{i}+2
$$

which equals the oxygen number of the cage, whereas the number of decorated faces $\sum f$ corresponds to the number of copper atoms. In the cubic $\mathrm{BaCuO}_{2}$ structure, the octahedral faces of the $\left[4^{6} 4^{12} 3^{8}\right]$ polyhedron are not occupied by $\mathrm{Cu}$. Therefore, the cage formula is found to be $\mathrm{Cu}_{6+12} \mathrm{O}_{24}$.

One may ask, which properties a cluster compound of corner-sharing cuprate stripes might show. A cluster, extending its cage diameter by $\sqrt{2}$ compared to the edge-sharing $\left[4^{6} 4^{12} 3^{8}\right]$ polyhedron, may be formed in the presence of a suitable template, for instance, $\mathrm{TMA}^{+}$or TMM. Figure 5 depicts a possible solution of $\mathrm{m} 3 \mathrm{~m}$ symmetry with the polyhedron notation $\left[4^{6} 4^{12} 4^{24} 3^{8}\right]$ and a diameter along [001] of about $9.39 \AA$. The polyhedron is constructed of copper-centred oxygen quadrilaterals corresponding to a cube in combination with a rhombic dodecahedron. The coordination of copper atoms of the dodecahedron is that of a very flat tetrahedral disphenoid with $\mathrm{O}-\mathrm{Cu}-\mathrm{O}$ bond angles around $122.4^{\circ}$ in order to adapt well the copper oxygen bond lengths. Such coordination is frequently observed, for example in the crystal structure of dioptase. Weakly deformed quadrilaterals of a further $\{211\}$ trapezohedron are expected to be occupied by copper, too. It should be stressed that the formerly corner-connected arrangement of the plaquettes (Figure 5) changes with this additional decoration to edge-connected ones (Figure 6). Finally, the polyhedron is closed by an octahedron.

If all faces of the polyhedron are occupied by copper, a formula of $\mathrm{Cu}_{46} \mathrm{O}_{48}^{4-}$ would result. The super-cages can be arranged in a cubic lattice of space group Im3m with a lattice parameter of $a=14.938 \AA$ in such a way that copper at the $1 / 4,1 / 4,1 / 4$ site connects neighbouring cages (Table 6). The cage separation from each other is chosen in such a way that a trigonally stretched oxygen 'octahedron' is arranged around this copper atom. The

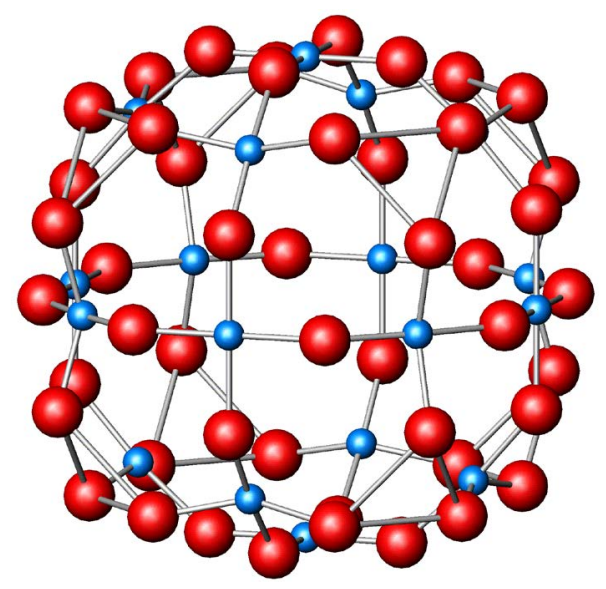

Figure 5. $\left[4^{6} 4^{12} 4^{24} 3^{8}\right]$ super-cage polyhedron with $9.39 \AA$ diameter down [001], showing for reasons of clarity, apart from red oxygen atoms, only the decoration of the $4^{6}$ and the $4^{12}$ faces with copper in light blue colour. This reduced decoration would lead to corner-sharing cuprate plaquettes. 
bond length of $1.894 \AA$ may be a bit small for this Jahn-Teller cation, but favours an occupation with highly charged other ions such as $\mathrm{Ge}^{4+}$. Even though one would somewhat enlarge the lattice parameter in order to match the ideal environment for copper in the $2+$ oxidation state, there is no need to change much the distance, if this cation is $3+$ charged.

In the [100] direction an additional oxygen atom at the $1 / 2,0,0$ site can bond the cages through elongated $\mathrm{CuO}_{5}$ pyramids. Then the unit-cell content amounts to 2 formula units of $\mathrm{Cu}_{46} \mathrm{O}_{51}^{10-}$, giving a calculated density of $\mathrm{D}_{\text {calc }}=3.73 \mathrm{~g} \cdot \mathrm{cm}^{-3}$. Charge compensation may be adapted by some $\mathrm{Cu}^{3+}$, equivalent to intrinsic $\mathrm{O}^{1-}$ hole doping, or by a few interstitial cations such as the large $\mathrm{Ba}^{2+}$, apart from the possibility of choosing positively charged template ions or $\mathrm{Ge}^{4+}$ instead of copper at the $8 \mathrm{c}$ site (Table 6). With the option to use cations other than copper one is inclined to speak of a cuprate compound, in the other case we are dealing simply with a cagey cupric oxide.

Atomic coordinate and bond length respectively bond angle of the hypothetic structure are given in Table 6 respectively Table 7. In addition, an X-ray powder pattern was calculated for rapid identification in case of synthesis success, characterized by two very strong peaks with d-values of $7.47 \AA$ respectively $6.10 \AA$ (see Table 8). The cluster calculation method is to refine a trial structure step by step using bond length and bond angles as geometrical constraints together with oxygen-oxygen distances, finally adapting the required bond valence sums. To calculate the $\mathrm{Cu}-\mathrm{O}$ bond valance sum by the empirical Brown relation $s=\Sigma\left(d / d_{0}\right)^{-N}[14]$ [15] the new coefficients $d_{0}=1.713(9) \AA$ and $\mathrm{N}=5.76(0.16)$ were used. The calculations were carried out using the software modules of Reference [26].

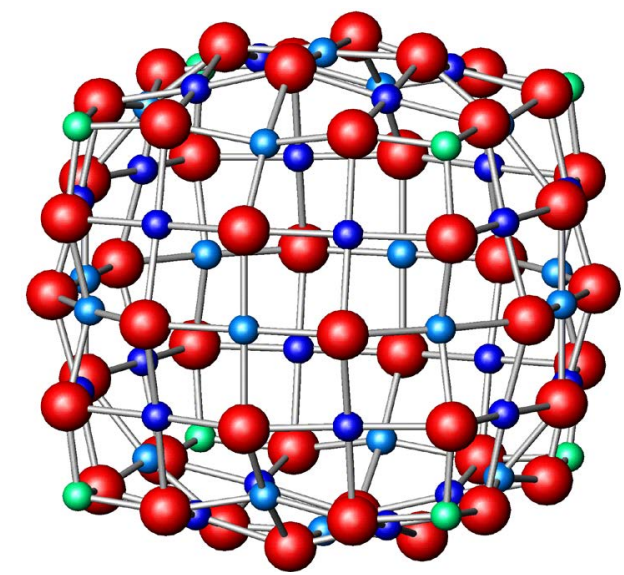

Figure 6. Fully decorated cuprate super-cage with $4^{6}$ and $4^{12}$ faces centered with light blue copper atoms, $4^{24}$ with blue ones respectively $4^{8}$ ones capped with green colored atoms. The cage deviates somewhat from a sphere towards a cube.

Table 6. Proposed atomic coordinates for a cluster structure of space group $\operatorname{Im} 3 m$ (No. 229) with the lattice parameter of $a=14.938 \AA$. Cage radii for the different ions are given as $r_{c}(\AA)$ $=a \cdot \sqrt{\left(x^{2}+y^{2}+z^{2}\right)}$ respectively $\left\langle r_{c}\right\rangle$ as ion-specific weighted ones. Further, an additionally electron number weighted radius $R(\AA)$ is introduced.

\begin{tabular}{ccccccc}
\hline Atoms & site & $x$ & $y$ & $z$ & $r_{c}$ & $\left\langle r_{c}>\right.$ \\
\hline $\mathrm{Cu}(1)$ & $12 \mathrm{e}$ & 0 & 0 & 0.31435 & 4.696 & \\
$\mathrm{Cu}(2)$ & $24 \mathrm{~h}$ & 0 & 0.22762 & 0.22762 & 4.809 & 4.877 \\
$\mathrm{Cu}(3)$ & $48 \mathrm{~m}$ & 0.12591 & 0.12591 & 0.28003 & 4.957 & \\
$\mathrm{Cu}(4)$ or $\mathrm{Ge}^{4+}$ & $8 \mathrm{c}$ & $1 / 4$ & $1 / 4$ & $1 / 4$ & - & - \\
$\mathrm{O}(1)$ & $48 \mathrm{j}$ & 0.12990 & 0 & 0.31330 & 5.066 & \\
$\mathrm{O}(2)$ & $48 \mathrm{k}$ & 0.12328 & 0.25270 & 0.25270 & 5.647 & 5.356 \\
$\mathrm{O}(3)$ & $6 \mathrm{~b}$ & $1 / 2$ & 0 & 0 & - & - \\
Mean polyhedron radius $R$, weighted by individual electron numbers $(\mathrm{Cu}=29, \mathrm{O}=8)$ & 4.981
\end{tabular}


Table 7. Calculated bond length $(\AA), \mathrm{Cu}-\mathrm{O}-\mathrm{Cu}$ bond angles $\left({ }^{\circ}\right)$ and bond valence sums $s$ of the super-cage structure.

\begin{tabular}{ccccc}
\hline Atoms & $\mathrm{O}(1)$ & $\mathrm{O}(2)$ & $\mathrm{O}(3)$ & $\mathrm{s}$ \\
\hline $\mathrm{Cu}(1)$ & $4 \times 1.9405$ & & 2.7733 & 2.00 \\
$\mathrm{Cu}(2)$ & $2 \times 1.9414$ & $2 \times 1.9163$ & 2.00 \\
$\mathrm{Cu}(3)$ & $2 \times 1.9463$ & $2 \times 1.9379$ & 3.94 & 4.00 \\
$\left.\mathrm{Cu}(4)^{*}\right)$ or $\mathrm{Ge}^{4+}$ & & $6 \times 1.8938$ & 3.400 & \\
$\mathrm{O}(1)$ & 2.744 & 2.753 & & \\
$\mathrm{O}(2)$ & & 2.734 & & \\
$\mathrm{Cu}(1)-\mathrm{O}-\mathrm{Cu}(1)$ & 139.2 & & \\
$\mathrm{Cu}(1)-\mathrm{O}-\mathrm{Cu}(2)$ & & 82.5 & \\
$\mathrm{Cu}(2)-\mathrm{O}-\mathrm{Cu}(3)$ & & 162.2 & \\
$\mathrm{Cu}(2)-\mathrm{O}-\mathrm{Cu}(4)$ & 122.1 & 114.3 & \\
$\mathrm{Cu}(3)-\mathrm{O}-\mathrm{Cu}(3)$ & & 122.8 & \\
$\mathrm{O}-\mathrm{Cu}(2)-\mathrm{O}$ & & & \\
\hline
\end{tabular}

*II this site could be actually filled with $\mathrm{Cu}^{2+}$ ions, then the lattice parameter can be adapted in order to enlarge the $\mathrm{Cu}(4)-\mathrm{O}$ bond length to a more realistic value near $2.07 \AA$.

Table 8. Calculated X-ray powder pattern of the super-cage structure $\left(\mathrm{Cu}-\mathrm{K} \alpha_{1}\right.$ radiation, $\left.\lambda=1.5406 \AA\right)$.

\begin{tabular}{|c|c|c|c|}
\hline $2 \Theta$ & d & $\mathrm{I}_{\text {calc }} / \mathrm{I}_{0}$ & hkl \\
\hline 8.364 & 10.563 & 17 & 110 \\
\hline 11.839 & 7.470 & 100 & 200 \\
\hline 14.513 & 6.098 & 92 & 211 \\
\hline 16.773 & 5.281 & $<1$ & 220 \\
\hline 18.770 & 4.724 & 6 & 310 \\
\hline 20.580 & 4.312 & 3 & 222 \\
\hline 22.249 & 3.992 & 18 & 321 \\
\hline 23.807 & 3.735 & 11 & 400 \\
\hline 25.275 & 3.521 & 5 & $330 / 411$ \\
\hline 26.666 & 3.340 & $<1$ & 420 \\
\hline 27.994 & 3.185 & $<1$ & 332 \\
\hline 29.266 & 3.049 & $<1$ & 422 \\
\hline 30.489 & 2.9295 & 23 & $510 / 431$ \\
\hline 32.812 & 2.7273 & 3 & 521 \\
\hline 33.920 & 2.6407 & 4 & 440 \\
\hline 34.997 & 2.5618 & 10 & $530 / 433$ \\
\hline 36.046 & 2.4897 & 11 & $600 / 442$ \\
\hline 37.069 & 2.4233 & 8 & $611 / 532$ \\
\hline 38.069 & 2.3619 & 2 & 620 \\
\hline 39.046 & 2.3050 & $<1$ & 541 \\
\hline 40.004 & 2.2520 & 1 & 622 \\
\hline 40.943 & 2.2025 & 4 & 631 \\
\hline 41.864 & 2.1561 & 13 & 444 \\
\hline 42.770 & 2.1126 & 12 & $550 / 710 / 543$ \\
\hline 43.660 & 2.0715 & $<1$ & 640 \\
\hline 44.535 & 2.0328 & 9 & $721 / 552 / 633$ \\
\hline
\end{tabular}


Since the suggested templates lack a centre of symmetry, one could adapt this fact to the cage structure, too, and hence would create an acentric space group such as I432 with more degrees of freedom to account for energetically favoured bond lengths and angles, respectively. However, this option has not been calculated in detail.

The cluster would shows different paths of $>90^{\circ}$ antiferromagnetic $\mathrm{Cu}-\mathrm{O}-\mathrm{Cu}$ super-exchange interaction (see Table 7), a prerequisite for superconductivity. For instance, the $\mathrm{Cu}(1)-\mathrm{O}-\mathrm{Cu}(2)$ bond angle amounts to $\Phi=$ $139.2^{\circ}$, resulting in an assumed principal super-exchange interaction of $J_{z}(\Phi)=0.091(\Phi-90)^{1.651} \mathrm{meV} \approx 56.6$ meV (see Figure 7 and [27], respectively).

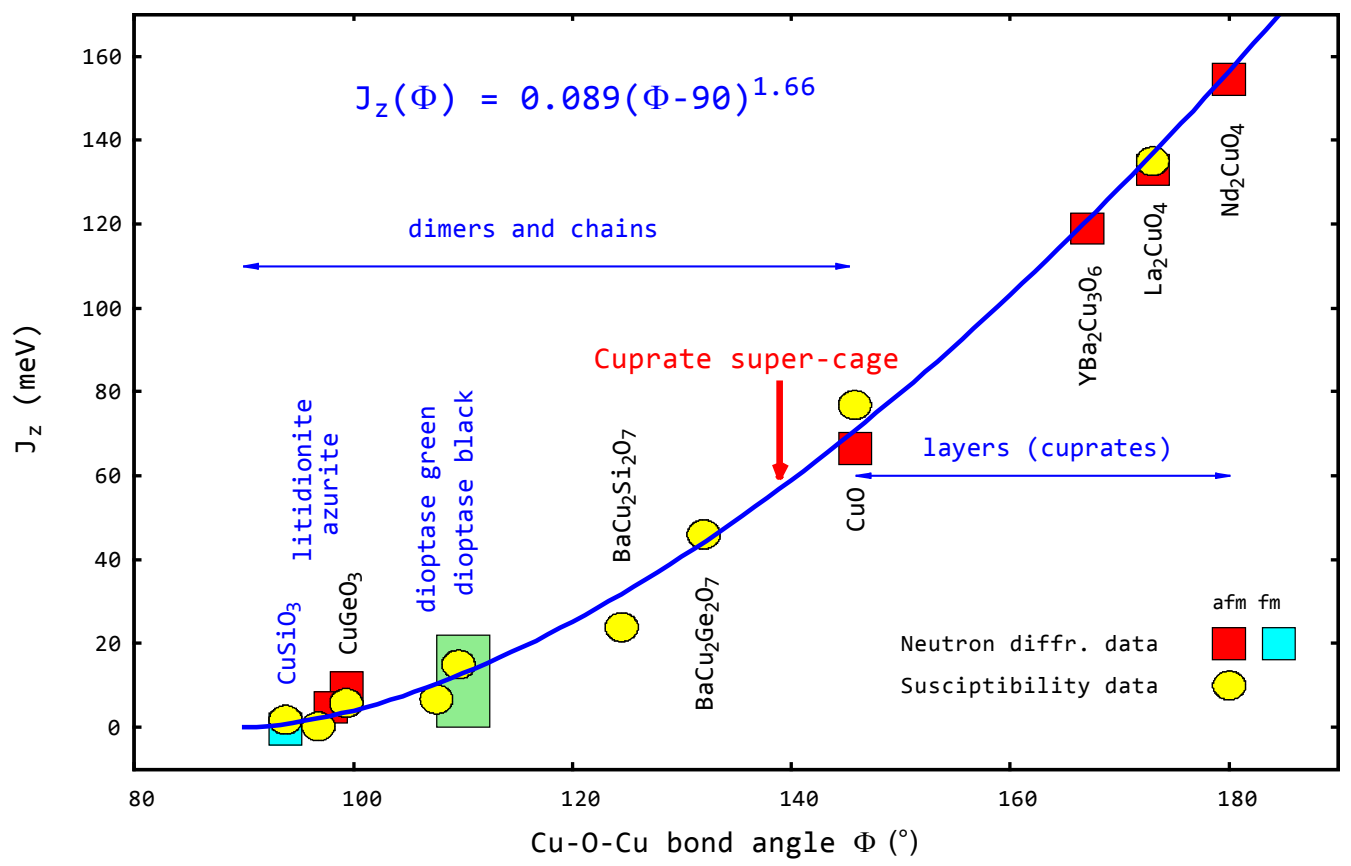

Figure 7. Principal super-exchange interaction $J_{z}(\Phi)$ versus $\mathrm{Cu}-\mathrm{O}-\mathrm{Cu}$ bond angle $\Phi(\mathrm{afm}=$ antiferromagnetic, $\mathrm{fm}=$ ferromagnetic). The red arrow marks the cuprate super-cage position. This relation was first published by Rocquefelte et al. [27]. Data for minerals outlined in blue like dioptase have been added and included in the $J_{z}(\Phi)$ fit by the present author.

The cluster compound is expected to carry a super-current through its lattice, when optimum doped. Besides superconductivity one should think about other properties like light-harvesting features for solar cell application, relying on ball antennas instead of linearly extended ones. In this case also other non-cage atoms such as iodine replacing oxygen or $\mathrm{Sn}^{4+}$ replacing $\mathrm{Ge}^{4+}$ should be also considered to enhance the solar efficiency.

A synthesis route is proposed as follows. First, ultrathin T-CuO films may be deposited onto a substrate such as (001)-oriented $\mathrm{SrTiO}_{3}$ by pulsed laser deposition (PLD) using a $\mathrm{CuO}$ target (Siemons et al. [28]; Samal et al. [29]). Then, this film is peeled off from the surface by assistance of a surfactant, simultaneously offering a template, around which T-CuO film fragments can roll up. The free accessible space of the super-cage to be filled with the template is about $6.63 \AA$ (smallest cage diameter of $9.39 \AA$ minus diameter of $2.76 \AA$ for an oxygen atom). Two quaternary organic templates of about the same Van der Waals dimension of $6.3 \AA$ are favoured to accomplish well such space filling: the cation $\mathrm{N}\left(\mathrm{CH}_{3}\right)_{4}^{+}\left(\mathrm{TMA}^{+}\right)$and $\mathrm{C}\left(\mathrm{CH}_{3}\right)_{4}(\mathrm{TMM})$, respectively. Finally, crystallization of a clusters structure may be supported by some suitable cations offered, which could interconnect the cages and provide charge neutrality.

Besides $\mathrm{SrTiO}_{3}$, as the most favourable substrate, one should consider also $\mathrm{BaO}$ in the rocksalt type, but considering the limitations formulated in the previous chapters.

\section{Characteristic of X-Ray Scattering from Hollow Polyhedral Structures}

The X-ray powder pattern of the cubic cuprate super-cage structure (Table 7) was calculated with the aid of the FullProf program (Carvajal [30]). It shows a pronounced intensity modulation of the peaks, which can be un- 
derstood as resulting from a uniform electron density distribution $\rho$ on the shell of a hollow sphere of radius $r_{s}$, approximating the empty polyhedral cage. Because the copper atoms, occupying the face centers of the polyhedron, have smaller distances to the cage center compared to the oxygen atoms at the corners, an electron density weighted radius $R$ will be introduced (see Table 5).

Calculating the structure factor $F(\boldsymbol{k})$ as the Fourier transform of the radial charge density $\rho(r)$, the property of the Dirac delta function $\delta$ is used, where the integral of $\delta$ times some other function $f(r)$ is equal to the value of $f(r)$ at the position of $\delta$ :

$$
\int f(r) \delta(r-R) \mathrm{d} r=f(R) .
$$

Following in part the calculation concept of Alloul and Lyle [31] applied to $\mathrm{C}_{60}$ buckyballs, one obtains the scale factor A from the total number $N_{e}$ of electrons of the polyhedron, confined to a shell of radius $\mathrm{R}$ as

$$
N_{e}=\int \rho(r) \mathrm{d}^{3} r=\int_{0}^{\infty} 4 \pi r^{2} \delta(r-R) A \mathrm{~d} r=4 \pi A R^{2}, A=N_{e} /\left(4 \pi R^{2}\right) .
$$

Using polar coordinates $r, \varphi, \theta$, for spherically symmetric functions, one obtains $\mathrm{d}^{3} r=r^{2} \mathrm{~d} r \mathrm{~d} \varphi \sin \theta \mathrm{d} \theta$. Then the Fourier transform yields

$$
\begin{gathered}
F(\boldsymbol{k})=\int \rho(r) \exp (-i \boldsymbol{k} \cdot \boldsymbol{r}) \mathrm{d}^{3} r \\
F(\boldsymbol{k})=A \int_{0}^{\infty} r^{2} \delta(r-R) \mathrm{d} r \int_{0}^{2 \pi} \mathrm{d} \varphi \int_{0}^{\pi} \exp (-i k r \cos \theta) \sin \theta \mathrm{d} \theta
\end{gathered}
$$

Substituting $\cos \theta=\zeta$ gives

$$
\int_{0}^{\pi} \exp (-i k r \cos \theta) \sin \theta \mathrm{d} \theta=\int_{+1}^{-1}(-1) \exp (-i k r \varsigma) \mathrm{d} \varsigma=2 \frac{\sin (k r)}{k r}
$$

Hence,

$$
F(\boldsymbol{k})=4 \pi A \int_{0}^{\infty} \frac{\sin (k r)}{k r} r^{2} \delta(r-R) \mathrm{d} r=4 \pi A R^{2} \frac{\sin (k R)}{k R}=N_{e} \frac{\sin (k R)}{k R}
$$

Finally, the intensity results as

$$
I(\boldsymbol{k})=|F(\boldsymbol{k})|^{2}=N_{e}^{2}\left(\frac{\sin (k R)}{k R}\right)^{2}
$$

Replacing $|\boldsymbol{k}|=k=2 \pi / d$ with the interplanar spacing $d=\lambda /(2 \sin \theta)=a / \sqrt{\left(h^{2}+k^{2}+l^{2}\right)}$, it can be seen that $I(\boldsymbol{k})$ shows zeros for $R / d=n / 2$ with integer $n$ and maxima near $R / d=(2 n+1) / 4$, respectively. A more exact solution, reflecting the slope of the denominator function, may be applied to calculate the radius $R$ from $d$ or $k$ values assigned to the 'corrected' maxima of order n:

$$
R=k^{-1} f(z)=k^{-1}\left(z-z^{-1}\right), \text { where } z=\pi\left(\frac{2 n+1}{2}\right) .
$$

In addition, the intensity $I(\boldsymbol{k})$ of an actual powder pattern has to be corrected for LpG factors and overall atomic displacement $\exp (-2 T)$, respectively. This was applied in Figure 8 to display the modulated intensity of the super-cage structure.

Subtracting this modulation from the actual pattern would indicate reflections with a pronounced contribution of non-cage atoms. It should be stressed that some complication results when the sphere is inflated towards a cube as shown above in Figure 6. The Fourier transform for such rounded cube will be calculated and published later.

The outlined concept is particularly favorable for the analysis of unknown cage structures. One can simply calculated the center of gravity $k_{g}$ of a batch of foremost intense reflections, corrected by LpG and exp(-2T), and therefrom determine the cage radius $R$ using Equation (11). This information may be important to rapidly solve the complete crystal structure. 
Although the chosen example of the super-cage model is not ideal insofar as it deviates somewhat from the spherical shape with diminishing characteristic diffraction features at high $k$ values, the recovery of the (predetermined) super-cage radius $R$ using Equation (11) gives still a remarkable result (see Table 9).

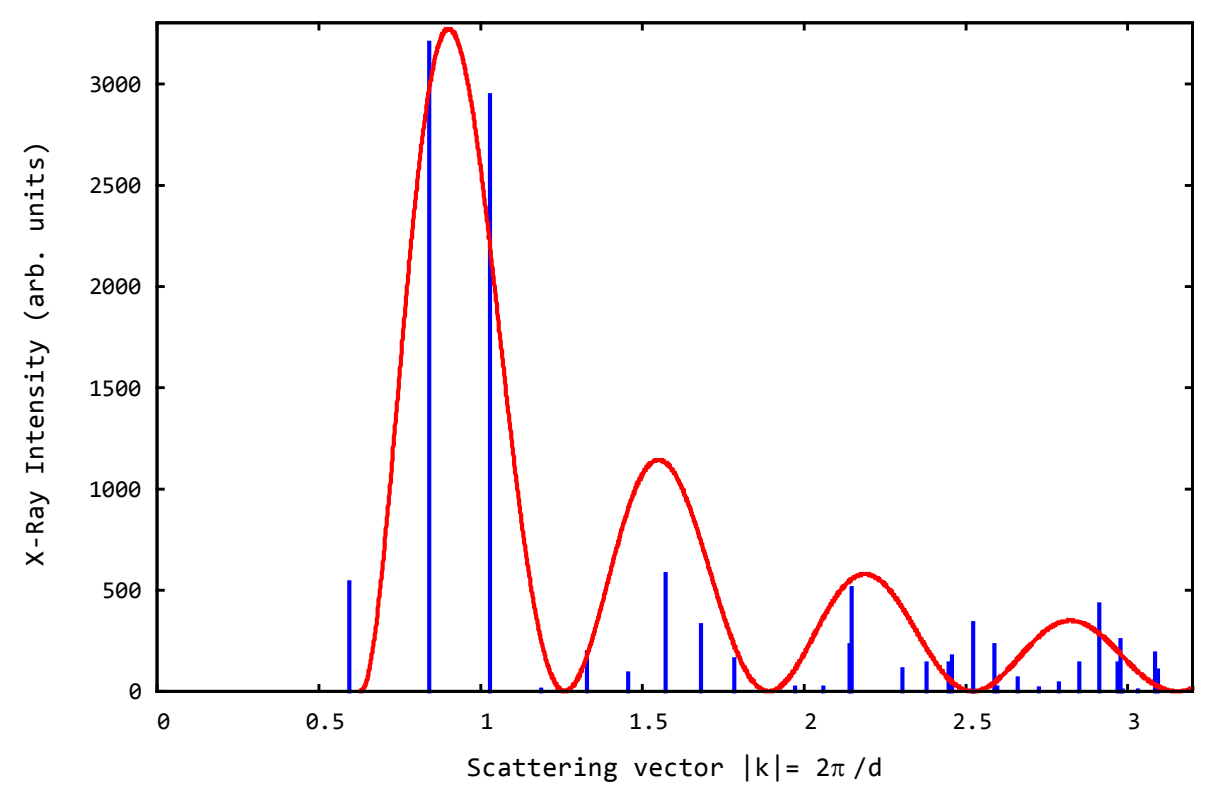

Figure 8. Spherical shell diffraction pattern (red) enveloping the super-cage X-ray powder pattern (blue). Coinciding reflections were slightly offset side by side.

Table 9. Redetermination of the cage radius $R$ from reflection batches around the maxima of $\mathrm{I}(\mathrm{k})$, yielding a mean value of $R=5.00 \AA$.

\begin{tabular}{cccc}
\hline Order of Maximum & $k^{-1}(\AA)($ center of gravity) & $f(z)$ & $R(\AA)=f(z) \cdot k^{-1}$ \\
\hline 1 & 1.1051 & 4.5002 & 4.973 \\
2 & 0.6631 & 7.7267 & 5.124 \\
4 & 0.4544 & 10.9046 & 4.965 \\
& 0.3528 & 14.0664 & 4.963 \\
\hline
\end{tabular}

\section{Conclusions}

Possible formation pathways of cupric oxide clusters of cubic $\mathrm{BaCuO}_{2}$ are analysed in this article. The author has entertained the idea to construct more voluminous $\mathrm{CuO}$ clusters, the larger radii of curvature of which allows greater than $90^{\circ} \mathrm{Cu}-\mathrm{O}-\mathrm{Cu}$ bonding angles and possible antiferromagnetic super-exchange interaction as a prerequisite for high- $T_{\mathrm{c}}$ superconductivity. An $\mathrm{Cu}(1)-\mathrm{O}-\mathrm{Cu}(2)$ exchange pathway within such $\mathrm{Cu}_{46} \mathrm{O}_{48}^{4-}$ super-cage of $9.39 \AA$ diameter shows a bond angle of $\Phi=139.2^{\circ}$. Cupric oxide super-cage formation around templates such as $\mathrm{TMA}^{+}$or TMM is suggested, whereby epitaxially grown ultrathin films of T-CuO are thought to deliver edge-connected $\mathrm{CuO}$ fragments that curl up around such guest molecules. Besides superconductivity the super-cage polyhedra can act in ball antennas for sunlight harvesting, when suitably doped, for instance with tin and iodine, respectively as inter-cage bonding entities.

An X-ray powder pattern was also calculated for a super-cage structure of space group $\operatorname{Im} 3 \mathrm{~m}$ and a lattice parameter of $14.938 \AA$. This identification possibility was supplemented by hollow sphere scattering calculations, approximating the electron distribution on the polyhedron through a radial shell electron density assumption. Characteristics of such X-ray scattering may serve to identify unknown hollow clusters. In addition, model calculations have suggested a new tetragonal $\mathrm{BaCuO}_{2}$ phase of space group $\mathrm{P} 4 / \mathrm{nmm}$ with up and down puckered pyramidal T-CuO nets, a possibly step towards edge-connected cluster formation. 
Research into novel copper oxide clusters may also stimulate associated scientific fields similar to carbon clusters with their full basket of remarkable properties, all the more so since the $\mathrm{T}-\mathrm{CuO}$ net shows similar lowenergy excitations as the $\mathrm{CuO}_{2}$ net of the known high- $\mathrm{T}_{\mathrm{c}}$ superconductors (Moser et al. [32]). Materials scientists are encouraged to attempt their synthesis.

\section{Acknowledgements}

The author wishes to thank Prof. Dr. R. B. Heimann for critical reading of the manuscript.

\section{References}

[1] Bednorz, J.G. and Müller, K.A. (1986) Possible High $\mathrm{T}_{\mathrm{c}}$ Superconductivity in the Ba-La-Cu-O System. Zeitschrift für Physik, B64,189-193. http://dx.doi.org/10.1007/BF01303701

[2] Müller-Buschbaum, H. (1989) Zur Kristallchemie der oxidischen Hochtemperatur-Supraleiter und deren kristallchemischen Verwandten. Zeitschrift für anorganische und allgemeine Chemie, 101, 1503-1524. http://dx.doi.org/10.1002/ange.19891011105

[3] Yvon, K. and François, M. (1989) Crystal Structures of High-T ${ }_{c}$ Oxides. The Years 1987 and 1988. Zeitschrift für Physik, B76, 413-444. http://dx.doi.org/10.1007/BF01307892

[4] Baltrusch, R. (1997) Zur Kristallchemie von Systemen oxidischer Hochtemperatursupraleiter. Dissertation, TU Clausthal, Clausthal-Zellerfeld.

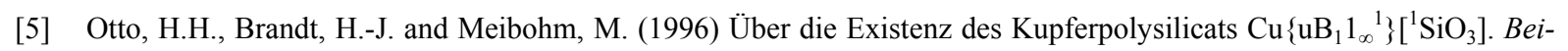
hefte zu European Journal of Mineralogy, 8, 206.

[6] Otto, H.H. and Meibohm, M. (1999) Crystal Structure of Copper Polysilicate, $\mathrm{Cu}\left[\mathrm{SiO}_{3}\right]$. Zeitschrift für Kristallographie, 214, 558-565. http://dx.doi.org/10.1524/zkri.1999.214.9.558

[7] Sigrist, T., Zahurak, S.M., Murphy, D.W. and Roth, R.S. (1988) The Parent Structure of the Layered High-Tem- perature Superconductors. Nature 334, 231-232. http://dx.doi.org/10.1038/334231a0

[8] Siemons, W. (2008) Nanoscale Properties of Complex Oxide Films. Ph.D. Thesis, University of Twente, Enschede.

[9] Jahn, H.A. and Teller, E. (1937) Stability of Polyatomic Molecules in Degenerate Electronic States. I. Orbital Degeneracy. Proceedings of the Royal Society, A161, 220-235. http://dx.doi.org/10.1098/rspa.1937.0142

[10] Woodley, S.M. and Catlow, R. (2008) Crystal Structure Predictions from First Principles. Nature Materials, 7, $907-$ 946. http://dx.doi.org/10.1038/nmat2321

[11] Forster, M.D., Simperler, A., Bell, R.G., Friedrich, O.D., Paz, F.A. and Klinowski, J. (2004) Chemically Feasible Hypothetical Crystalline Networks. Nature Materials, 3, 234-238. http://dx.doi.org/10.1038/nmat1090

[12] Schein, S. and Gayed, J.M. (2014) Fourth Class of Convex Equilateral Polyhedron with Polyhedral Symmetry Related to Fullerenes and Viruses. Proceedings of the National Academy of Sciences of the United States of America, 111, 2920-2925. http://dx.doi.org/10.1073/pnas.1310939111

[13] Zhai, H.-J., Zhao, Y.-F., Li, W.-L., Chen, Q., Bai, H., Hu, H.-S., Piazza, Z.A., Tian, W.-J., Lu, H.-G., Wu, Y.-B., Mu, Y.-W., Wie, G.-F., Liu, Z.-P., Li, J., Li, S.-D. and Wang, L.-S. (2014) Observation of an All-Boron Fullerene. Nature Chemistry, 6, 727-731. http://dx.doi.org/10.1038/nchem.1999

[14] Brown, I.D. and Shannon, R.D. (1973) Empirical Bond-Strength-Bond-Length Curves for Oxides. Acta Crystallographica Section A, 29, 266-282. http://dx.doi.org/10.1107/S0567739473000689

[15] Brown, I.D. (1981) The Bond-Valence Method: An Empirical Approach to Chemical Structure and Bonding. Structure and Bonding in Crystals. Volume II, Academic Press, New York.

[16] Zhu, S., Norton, D.P., Chamberlain, J.E., Shahedipour, F. and White, H.W. (1996) Evidence of Apical Oxygen in Artificially Superconducting $\mathrm{SrCuO}_{2}-\mathrm{BaCuO}_{2}$ Thin Films: A Raman Characterization. Physical Review B, 54, 97-100. http://dx.doi.org/10.1103/PhysRevB.54.97

[17] Schönberger, R., Otto, H.H., Brunner, B. and Renk, K.F. (1991) Evidence for Filamentary Superconductivity up to 220 $\mathrm{K}$ in Oriented Multiphase Y-Ba-Cu-O Thin Films. Physica C: Superconductivity, 173, 159-162. http://dx.doi.org/10.1016/0921-4534(91)90363-4

[18] Azzoni, C.B., Paravicini, G.B.A., Samoggia, G., Ferloni, P. and Parmigiani, F. (1990) Electrical Instability in CuO $\mathrm{C}_{1-\mathrm{x}}$ : Possible Correlations with the CuO-Based High Temperature Superconductors. Zeitschriftfür Naturforschung, A45, 790-794.

[19] Osipov, V.V., Kochev, I.V. and Naumov, S.V. (20010) Giant Electric Conductivity at the CuO-Cu Interface: HTSL-Like Temperature Variations. Journal of Experimental and Theoretical Physics, 93, 1082-1090. 
[20] Mitkin, A.V. (2012) Striped Organization of Hole Excitations and Oxygen Interstitials in Cuprates as a Route to Room-Temperature Superconductivity. Journal of Superconductivity and Novel Magneti, 25, 1277-1281.

[21] Liu, L. and Bassett, W.A. (1972) Effect of Pressure on the Crystal Structure and Lattice Parameters of BaO. Journal of Geophysical Research, 77, 4934-4937. http://dx.doi.org/10.1029/JB077i026p04934

[22] Kimura, T, Goto, T., Shintani, H., Ishizaka, K., Arima, T. and Tokura, Y. (2003) Magnetic Control of Ferroelectric Polarization. Nature, 426, 55-58. http://dx.doi.org/10.1038/nature02018

[23] Kimura, T., Sekio, Y., Nakamura, H., Siegrist, T. and Ramirez, A.P. (2008) Cupric Oxide as an Induced-Multiferroic with High- $T_{c}$. Nature Materials, 7, 291-294. http://dx.doi.org/10.1038/nmat2125

[24] Ramirez, A.P., Broholm, C.I., Cava, R.J. and Kowach, G.R. (2000) Geometrical Frustration, Spin Ice and Negative Thermal Expansion-The Physics of Under-Constraint. Physica B, 280, 290-295. http://dx.doi.org/10.1016/S0921-4526(99)01695-6

[25] Euler, L. (1752) Elementa doctrine solidorum. Novi commentarii academiae scientiarum imperialis petropolitanae, 4 , 109-160.

[26] Otto, H.H. (1980) Manual for Turbo-Basic Crystal Structure Programs: Strufit, Guinkorr, Binwin, Bondval. Regensburg University, Regensburg.

[27] Rocquefelte, X., Schwarz, K. and Blaha, P. (2012) Theoretical Investigation of the Magnetic Exchange Interaction in Copper(II) Oxides under Chemical and Physical Pressures. Scientific Reports, 2, Article No. 759. http://dx.doi.org/10.1038/srep00759

[28] Siemons, W., Koster, G., Blank, D.H.A., Hammond, R.H., Geballe, T.H. and Beasley, M.R. (2009) Tetragonal CuO: End Member of the 3d Transition Metal Monoxides. Physical Review B, 79, Article ID: 195122. http://dx.doi.org/10.1103/PhysRevB.79.195122

[29] Samal, D., Tan, H., Takamura, Y., Siemons, W., Verbeeck, J., Van Tendeloo, G., Arenholz, E., Jenkins, C.A., Rijnders, G. and Koster, G. (2014) Direct Structural and Spectroscopic Investigation of Ultrathin Films of Tetragonal CuO: Six-Fold Coordinated Copper. Europhysics Letters, 105, Article ID: 17003. http://dx.doi.org/10.1209/0295-5075/105/17003

[30] Carvajal, J.R. (2004) Introduction to the Program FULLPROF. Laboratoire Leon Brillon (CEA-CNRS), Saclay France.

[31] Alloull, H. and Lyle, S. (2010) Introduction to the Physics of Electrons in Solids. E-Book, Springer Verlag, Berlin.

[32] Moser, S. Moreschini, L. Yang, H.-Y., Innocenti, D., Fuchs, F., Hansen, N.H., Chang, Y.J., Kim, K.S., Walter, A.L., Bostwick, A., Rotenberg, E., Mila, F. and Grioni, M. (2014) Angle-Resolved Photoemission Spectroscopy of Tetragonal CuO: Evidence for Intralayer Coupling between Cupratelike Sublattices. Physical Review Letters, 113, Article ID: 187001. http://dx.doi.org/10.1103/PhysRevLett.113.187001

[33] Takano, M., Takeda, Y., Okada, H., Miyamoto, M. and Kusaka, T. (1989) $\mathrm{A} \mathrm{CuO}_{2}$ (A: Alkaline Earth) Crystallizing in a Layered Structure. Physica C, 159, 375-378. http://dx.doi.org/10.1016/S0921-4534(89)80007-3

[34] Sakurai, T., Sugii, N., Takizawa, H., Ichikawa, M., Yaegashi, Y., Adachi, S., Shimada, M. and Yamauchi, H. (1992) $\mathrm{Ba}_{0.5} \mathrm{Sr}_{0.5} \mathrm{CuO}_{2}$ : A New Perovskite Related Structure Which Forms at High Pressure. Physica C, 193, 471-475. http://dx.doi.org/10.1016/0921-4534(92)90973-G

[35] Karpinsky, J., Schwer, H., Mangelshots, I., Conder, K., Morawski, A., Lade, T. and Paszewin, A. (1994) Single crystals of $\mathrm{Hg}_{1-x} \mathrm{~Pb}_{x} \mathrm{Ba}_{2} \mathrm{Ca}_{n-1} \mathrm{Cu}_{n} \mathrm{O}_{2 n+1-\delta}$ and Infinite-Layer $\mathrm{CaCuO}_{2}$. Synthesis at Gas Pressure of $10 \mathrm{kbar}$, Properties and Structure. Physica C, 234, 10-18. http://dx.doi.org/10.1016/0921-4534(94)90047-7

[36] Takano, M., Azuma, M., Bando, Y. and Takeda, Y. (1991) Superconductivity in the Ba-Sr-Cu-O System. Physica C, 176, 441-444.

[37] Teske, C.L. and Müller-Buschbaum, H. (1970) Über Erdalkalimetallcuprate. V. Zur Kenntnis von $\mathrm{Ca}_{2} \mathrm{CuO}_{3}$ und $\mathrm{SrCuO}_{2}$. Zeitschrift für anorganische und allgemeine Chemie, 379, 234.

[38] Smith, M.G., Manthiram, A., Zhou, J., Goodenough, J.B. and Markert, J.T. (1991) Electron-Doped Superconductivity at $40 \mathrm{~K}$ in the Infinite-Layer Compound $\mathrm{Sr}_{1-y} \mathrm{Nd}_{y} \mathrm{CuO}_{2}$. Nature, 351, 549-551. http://dx.doi.org/10.1038/351549a0

[39] Er, G., Miyamoto, Y., Kanamaru, F. and Kikkawa, S. (1991) Superconductivity in the Infinite-Layer Compound $\mathrm{Sr}_{1-x} \mathrm{La}_{x} \mathrm{CuO}_{2}$. Physica C, 181, 206-208. http://dx.doi.org/10.1016/0921-4534(91)90356-4

[40] Hiroi, Z., Azuma, M., Takano, M. and Bando, Y. (1991) A New Family of Copper Oxide Superconductors $\mathrm{Sr}_{n+2} \mathrm{Cu}_{n} \mathrm{O}_{2 n+1+\delta}$ Stabilized at High Pressure. Physica $C$, 188-189, 523-524. http://dx.doi.org/10.1016/0921-4534(91)92064-I

[41] Azuma, M., Hiroi, Z., Takano, M., Bando, Y. and Takeda, Y. (1992) Superconductivity at $110 \mathrm{~K}$ in the Infinite-Layer Compound $\left(\mathrm{Sr}_{1-x} \mathrm{Ca}_{x}\right)_{1-y} \mathrm{CuO}_{2}$. Nature, 356, 775-776. http://dx.doi.org/10.1038/356775a0

[42] Hiroi, Z., Azuma, M., Takano, M. and Takeda, Y. (1993) Structure and Superconductivity in the Infinite-Layer Com- 
pound $\left(\mathrm{Ca}_{1-y} \mathrm{Sr}_{y}\right)_{1-x} \mathrm{CuO}_{2-z}$. Physica C, 208, 286-296. http://dx.doi.org/10.1016/0921-4534(93)90200-A

[43] Adachi, S., Yamauchi, H., Tanaka, S. and Mori, N. (1993) High-Pressure Synthesis of Superconducting Sr-Ca-Cu-O Samples. Physica C, 208, 226-230. http://dx.doi.org/10.1016/0921-4534(93)90192-S

[44] Adachi, S., Yamauchi, H., Tanaka, S. and Mori, N. (1993) New Superconducting Cuprates in the Sr-Ca-Cu-O System. Physica C, 212, 164-168. http://dx.doi.org/10.1016/0921-4534(93)90498-F

[45] Sugii, N., Ichikawa, M., Hayachi, K., Kubo, K., Yamamoto, K. and Yamauchi, H. (1993) Microstructure of the Infinite-Layer Structural $\mathrm{Sr}_{1-x} \mathrm{CuO}_{2-d}$ Thin Films. Physica C, 213, 345-352. http://dx.doi.org/10.1016/0921-4534(93)90451-U

[46] Li, X., Kanai, M., Kawai, T. and Kawai, S. (1993) Epixial Growth and Properties of $\mathrm{Ca}_{1-x} \mathrm{Sr}_{x} \mathrm{CuO}_{2}$ Thin Films ( $\mathrm{x}=0.18$ to 1.0) Prepared by Co-Deposition and Atomic Layer Stacking. Japanese Journal of Applied Physics, 31, L217-L220. http://dx.doi.org/10.1143/JJAP.31.L217

[47] Terashima, Y., Sato, R., Takeno, S., Nakamura, S. and Miura, T. (1993) Preparation of Epitaxial $\mathrm{SrCuO}_{\mathrm{x}}$ Thin Films with an Infinite-Layer Structure. Japanese Journal of Applied Physics, 32, L48-L50. http://dx.doi.org/10.1143/JJAP.32.L48

[48] Maeda, T., Yoshimoto, M., Shimozono, K. and Koinuma, H. (1995) Two-Dimensional Laser Molecular Beam Epitaxy and Carrier Modulation of Infinite-Layer $\mathrm{BaCuO}_{2}$ Films. Superconductivity, 247, 142-146. http://dx.doi.org/10.1016/0921-4534(95)00067-4

[49] Wang, J., Rak, Z., Zhang, F., Ewing, R.C. and Becker, U. (2011) Electronic Structure and Energetics of Tetragonal $\mathrm{SrCuO}_{2}$ and Its High-Pressure Superstructure Phase. Jounal of Physics: Condensed Matter, 23, Article ID: 465503.

[50] Kipka, R. and Müller-Buschbaum, H. (1977) Über Oxocuprate. XX Ein Erdalkalimetallcuprat (II) mit geschlossenen Baueinheiten. Zeitschrift für Naturforschung, 32, 121.

[51] Weller, M.T. and Lines, D.R. (1989) Structure and Oxidation State Relationship in Ternary Copper Oxides. Journal of Solid State Chemistry, 82, 21-29. http://dx.doi.org/10.1016/0022-4596(89)90217-X

[52] Insausti, M., Lezama, L., Cortés, R., Gil de Muro, I., Rojo, T. and Arriortua, M.I. (1995) Evolution with Time of the Magnetic and Spectroscopic Properties of the $\mathrm{BaCuO}_{2+\delta}$ Phase. Study of $\mathrm{Ba}_{1-x} \mathrm{Sr}_{x} \mathrm{CuO}_{2+\delta}$ Solid Solution. Solid State Communications, 93, 823-929. http://dx.doi.org/10.1016/0038-1098(94)00876-0

[53] Wang, Z.-R., Wang, X.-L., Fernandez-Baca, J.A., Johnston, G.C. and Vaknin, D. (1994) Antiferromagnetic Ordering and Paramagnetic Behaviour of Ferromagnetic $\mathrm{Cu}_{6}$ and $\mathrm{Cu}_{18}$ Clusters in $\mathrm{BaCuO}_{2+x}$. Science, 264, 202-204. http://dx.doi.org/10.1126/science.264.5157.402 


\section{A1. Supplementary Information Used in Table 1 and Figure 3, Respectively}

Of all available information about the $a$ lattice parameters for superconducting cuprates and related phases build-up of square-planar $\mathrm{CuO}_{2}$ layers and containing high $\mathrm{Ba}$ content, the upper limit appears to be $3.96 \AA$. The dependence of lattice parameters on the averaged alkaline earth ion radius of the parent structure compounds was first illustrated by Takano et al. [33] and then by Sakurai et al. [34]. In Figure 3 this data, including the data subsequently reported for $\mathrm{CaCuO}_{2}, \mathrm{Ba}_{0.5} \mathrm{Sr}_{0.5} \mathrm{CuO}_{2}$ and $\mathrm{BaCuO}_{2}$ compounds, are drawn differently to support my intention. However, some details need a further consideration. In Figure 3 straight lines represent results of a linear regression using only the first five consecutive lattice parameter values. Extrapolation to the pure Ca compound revealed the parameters $a=3.85 \AA$ and $c=3.17 \AA$ in agreement with the experimental results of Karpinsky et al. [35]. Takano et al. [36] reported extrapolated values of $3.849 \AA$ and $3.160 \AA$, respectively. Of the pure Sr compound to the few available compounds with substituted $\mathrm{Ba}$ for $\mathrm{Sr}$ the $a$ lattice parameters deviate from the linear curve to yield an upper value of about $3.93 \AA$. However, a quadratic regression curve extends well to the $3.96 \AA$ value of the fictive $\mathrm{BaCuO}_{2}$. In a more complicated manner behaves the $c$ lattice parameter on substitution of $\mathrm{Ba}$. The compounds with high $\mathrm{Ba}$ content show $c$ lattice parameters and densities, deviating more strongly to lower or higher values as expected from the assumed trend. Takano et al. (1989) [33] did not explicitly report the lattice parameters for $\mathrm{Ba}_{0.33} \mathrm{Sr}_{0.67} \mathrm{CuO}_{2}$ that I extracted from their picture given and from the related X-ray powder pattern. However, the peaks on this pattern are very broad. In addition, some peaks exist at low diffraction angles of the pattern that $\mathrm{I}$ attribute to the presence of cubic $\mathrm{BaCuO}_{2}$. Hence, the given $\mathrm{Ba}_{0.33} \mathrm{Sr}_{0.67} \mathrm{CuO}_{2}$ composition may be altered to one with slightly lower Ba content. However, the Ba-rich compound $\mathrm{Ba}_{0.5} \mathrm{Sr}_{0.5} \mathrm{CuO}_{2}$ may be a special case as its structure exhibits an ordering of the $\mathrm{Sr}$ and $\mathrm{Ba}$ ions in layers parallel to (001) with a different layer thickness of $3.64 \AA$ and $4.29 \AA$, respectively. At first sight the large separation of the Ba layer appears to contradict my hypothesis further explained below. Given the $a$ lattice parameter constraint as a result of tensile stress of the $\mathrm{CuO}_{2}$ net, the distinct bond strength of the two ions are leading to the different layer thickness observed, and consequently the structure expands in the $c$ direction. The cationic ordering may be energetically favourable. One could argue that Sr layers, located between two Ba layers, can act as a sort of substrate for the Ba layer to grow upon and thus stabilize this layer. Whatever the argument is, the result is a compound near the stability limit of the infinite layer prototype with a remarkably low density of about $\mathrm{D}_{\mathrm{x}}=5.64 \mathrm{~g} \cdot \mathrm{cm}^{-3}$, showing for the first time that the lattice parameter $c^{\prime}=c / 2$ (because of the cell doubling) exceeds the $a$ parameter by only a small margin. Owing to this complication the third-order regression curve in Figure 3 may be taken only as guide to the eye to indicate the tendency of the $c$ lattice parameter development up to the fictive $\mathrm{BaCuO}_{2}$ composition. It should be stressed that for the actual member of the $\mathrm{Ba}_{0.5} \mathrm{Sr}_{0.5} \mathrm{CuO}_{2}$ solid solution the structural change from tetragonal to orthorhombic with lattice parameters of $a=3.92 \AA$ and $b$ $=3.94 \AA$ already indicates that the otherwise squared $\mathrm{CuO}_{2}$ net may suffer a lateral distortion in compositions with high Ba content.

\section{A2. History of Synthesis Routes and Crystal Chemistry of Infinite Layer Cuprates and $\mathrm{Cubic} \mathrm{BaCuO}_{2}$}

First, additional details will be summarized that have been reported on the crystal-chemistry and materials synthesis effort of both compounds. This may lead to better understanding of the crystallographic conclusion drawn from this information. In the course of superconductor research different compounds, isostructural or similar to the parent structure, have been obtained. Some of these compounds show superconducting properties, if hole-doping by off-stoichiometry or electron-doping by substitution of elements with higher valence is done. Table 1 summarizes these infinite-layer compounds with their lattice parameters. The $\mathrm{CaCuO}_{2}$ end member does not exist under ambient conditions as a stable compound of this structure type, but can be prepared under high gas pressure together with a defined oxygen partial pressure. The resulting compound shows a small off-stoichiometry of about $\mathrm{Ca}_{0.98} \mathrm{CuO}_{2}$ (Karpinsky et al. [35]). The lattice parameters were determined to be $a=$ $3.8556(6) \AA$ and $c=3.1805(4) \AA$. The infinite layer compound is found as building unit in many high $\mathrm{T}_{\mathrm{c}}$ superconductors, the lattice parameters of which may also be derived from an extrapolation of the parameters for these compounds. In addition, the other end member $\mathrm{BaCuO}_{2}$, as already mentioned, is non-existent as unstrained parent structure type, but can be formed as a highly strained epitaxially grown compound. The fictive parameters for the non-strained compound are obtained by bond strength - bond length calculation.

The application of high pressure to transform the less dense compounds of the orthorhombic $\mathrm{SrCuO}_{2}$ structure 
type (Teske and Müller-Buschbaum [37] to the denser type of the infinite-layer structure was first reported by Takano et al. [33]. The phases $\mathrm{Sr}_{1 / 3} \mathrm{Ca}_{2 / 3} \mathrm{CuO}_{2}$ and $\mathrm{SrCuO}_{2}$ have been obtained. Whereas non superconducting in its ambient pressure prototypic composition, the newly discovered infinite-layer phase became an electrondoped superconductor by substitution of some alkaline earth ions by $\mathrm{Nd}^{3+}$. Understanding the importance of the in-plane bond length of $\mathrm{CuO}_{2}$ nets for the appearance of superconducting properties, Smith et al. [38] obtained the compound $\mathrm{Sr}_{0.84} \mathrm{Nd}_{0.16} \mathrm{CuO}_{2}$ at $1273 \mathrm{~K}$ and $25 \mathrm{MPa}$ with a transition temperature of $40 \mathrm{~K}$, remarkably high for an n-type material. Meanwhile $\mathrm{T}_{\mathrm{c}}$ could be enhanced to $\leq 43 \mathrm{~K}$ (Er et al. [39]). Hiroi et al. [40] pressed their cuprate samples isostatically up to $6 \mathrm{GPa}$ at $1273 \mathrm{~K}$ and succeeded in the synthesis of the first p-type superconductor $\mathrm{Sr}_{1-\mathrm{x}} \mathrm{CuO}_{2}\left(\mathrm{~T}_{\mathrm{c}}=100 \mathrm{~K}\right)$ of the infinite-layer type. Later, Azuma et al. [41] prepared under similar conditions compounds ranging from $\mathrm{Ca}_{2 / 3} \mathrm{Sr}_{1 / 3} \mathrm{CuO}_{2}$ through $\mathrm{SrCuO}_{2}$ to $\mathrm{Ba}_{1 / 3} \mathrm{Sr}_{2 / 3} \mathrm{CuO}_{2}$. Azuma et al. [41] and Hiroi et al. [42] reported on an alkaline earth-deficient sample $\left(\mathrm{Ca}_{1-\mathrm{y}} \mathrm{Sr}_{\mathrm{y}}\right)_{1-\mathrm{x}} \mathrm{CuO}_{2-\mathrm{z}}$ with a transition temperature of $110 \mathrm{~K}$ characterized by defect layers of alkaline earth vacancies almost randomly inserted into the parent structure.

With an already high $\mathrm{Ba}$ content the non-superconducting compound $\mathrm{Ba}_{0.5} \mathrm{Sr}_{0.5} \mathrm{CuO}_{2}$ has been observed by Sakurai et al. [34] formed at $1473 \mathrm{~K}$ under a high pressure of $6 \mathrm{GPa}$ for $2 \mathrm{~h}$. This phase is orthorhombic with lattice parameters $a=3.92 \AA, b=3.94 \AA$ and $c=2 \cdot 3.965 \AA$, space group Pmmm. The doubling of the $c$ parameter is attributed to the ordering of the alkaline earth ions $\mathrm{Ba}$ and $\mathrm{Sr}$ in separate sheets parallel to (001), but the wide FWHM of the reflections may be due to non-uniform ordering. Furthermore, a superstructure in the a-b plane was found. The reported lattice parameters were discussed in chapter A1 in more details.

Further investigations performed by Adachi et al. [43] [44] reported the formation of some stoichiometric infinite-layer compositions under high pressure and their decomposition with increasing, but nevertheless small uptake of oxygen beyond two in the formula unit.

Another synthesis route was successfully carried out to prepare infinite-layer phases by depositing epitaxial thin films on (001)-oriented $\mathrm{SrTiO}_{3}$ single crystal substrates at about $843 \mathrm{~K}$ (Sugii et al. [45]; Li et al. [46]; Terashima et al. [47]).

Finally, Maeda et al. [48] reported the two-dimensional laser beam epitaxy of infinite-layer $\mathrm{BaCuO}_{2}$ with a strain-expanded lattice parameter of $c=4.08 \AA$, whereas the $a$ parameter was found difficult to determine due to the air-sensitivity of the surface. A mean value around $3.90 \AA$ may be derived from the unit-cell volume.

On a properly chosen substrate the crystal lattice of the thin film is put under considerable compressive strain imitating high pressure conditions, but the compression in the plane of the film causes an expansion perpendicular to it. Therefore, since the lattice parameters of thin films may be altered in comparison with those of the bulk material the reported values have to be treated with some caution.

Recently, first principle calculations were applied to unravel the electronic structure of $\mathrm{SrCuO}_{2}$ with both the simple parent structure and the high-pressure superstructure, existing in the space group $\mathrm{P} \overline{4} \mathrm{~m} 2$ as a subgroup of $\mathrm{P} 4 / \mathrm{mmm}[49]$.

The complex crystal structure of cubic $\mathrm{BaCuO}_{2}$, the second prototype considered, was solved by Kipka \& Müller-Buschbaum [50]. Distinct copper-oxygen clusters were found in the unit cell with space group $\operatorname{Im} 3 \mathrm{~m}$. The largest cluster is a 26-hedron with 24 vertices and 48 edges, occupied by one of the soft $\mathrm{Ba}^{2+}$ with a surrounding of 24 oxygen atoms, and composed of 18 quadrilaterals and 8 triangles. It represents a combination of a cube, a rhombic dodecahedron and an octahedron. Thus the polyhedron notation is written as $\left[4^{6} 4^{12} 3^{8}\right]$ or simply as $\left[4^{18} 3^{8}\right]$. The quadrilaterals are centred by $\mathrm{Cu}^{2+}$. This large sphere cluster of $\mathrm{Cu}_{18} \mathrm{O}_{24}$ composition is located at $0,0,0$ and 1/2,1/2,1/2. In addition, 8-ring clusters of composition $\mathrm{Cu}_{6} \mathrm{O}_{12}$ are suggested to be at the position $1 / 4,1 / 4,1 / 4$ of the unit cell, apart from further 6 lone $\mathrm{CuO}_{4}$ units to complete the unit cell content to $\mathrm{Z}=90$. It then remains to explain why in the description of the crystal structure such large number of general sets and special ones of equivalent positions add up to the simple $\mathrm{BaCuO}_{2}$ stoichiometry, even though one site for $\mathrm{Cu}$ and oxygen show only partial occupation. Weller and Lines [51] have demonstrated that by thermal treatment at $1073 \mathrm{~K}$ in air or pure oxygen atmosphere the oxygen site in question may be slightly filled up from 0.25 to 0.379 atoms, leading to the formula $\mathrm{BaCuO}_{2.07}$, whereas stoichiometric material can be prepared under vacuum at 673 K.

From an unreasonably high displacement factor for the $\mathrm{Ba}$ atom on the origin the authors concluded that an unoccupied site exists, giving at least the formulas $\mathrm{Ba}_{0.98} \mathrm{CuO}_{2}$ and $\mathrm{Ba}_{0.98} \mathrm{CuO}_{2 \cdot 07}$, respectively. Indeed, on the one hand the very long bonds of $3.926 \AA$ between the 24 oxygen atoms and $\mathrm{Ba}$ in the central position would contribute just $28.2 \%$ of the required bond strength of +2 . On the other hand, the conclusion drawn from the displacement factor does not indicate evidence for an empty position. It is rather assumed that this Ba atom occu- 
pies an off-centre position and shows a rapid agitation between the distinct symmetry-allowed sites. The cluster cage is too large even for the soft $\mathrm{Ba}^{2+}$ ion.

Soon thereafter, Insausti et al. [52] reported the preparation of the $\mathrm{Ba}_{1-\mathrm{x}} \mathrm{Sr}_{\mathrm{x}} \mathrm{CuO}_{2+\delta}$ solid solution by thermal decomposition of metallo-organic complexes and investigated its magnetic and spectroscopic properties. The presence of $\mathrm{Sr}$ modifies the magnetic properties and reduces the ferromagnetic interaction. The substitution of $\mathrm{Sr}$ for $\mathrm{Ba}$ could be demonstrated up to $\mathrm{x}=0.4$, but the lattice parameter reduces only slightly from $18.272(1) \AA(\mathrm{x}=$ $0)$ to 18.181(1) $\AA(\mathrm{x}=0.4)$. This behaviour may be attributed to the stiffness of the large cuprate clusters and their connection through lone cuprate units along the main crystal axes without any bonding contribution of the alkaline earth ions in these directions.

Turning again to physical properties, Wang et al. [53] revealed the magnetic structure of $\mathrm{BaCuO}_{2+\mathrm{x}}$ by magnetization and neutron diffraction measurements. The individual clusters order ferromagnetically. Among the ring clusters an $\mathrm{AF}$ order was observed below $15 \mathrm{~K}$, whereas among the spherical clusters paramagnetic order remains down to $2 \mathrm{~K}$.

In summary, with respect to the alkaline earth content the parent structure exists up to the limiting concentration range of $\mathrm{Ba}_{0.5} \mathrm{Sr}_{0.5} \mathrm{CuO}_{2}$ under high pressure condition, and further up to pure $\mathrm{BaCuO}_{2}$, but only in highly strained thin films, whereas the $\mathrm{BaCuO}_{2}$ prototypic structure exists down to $\mathrm{Ba}_{0.6} \mathrm{Sr}_{0.4} \mathrm{CuO}_{2}$ under ambient pressure condition.

In this appended chapter a large part of published work about the parent structure and $\mathrm{BaCuO}_{2}$ has put together in order to develop the new idea of the possible formation of large antiferromagnetic cuprate cages respective cupric oxide ones. 